\title{
Optimization of Travelling Water Screen (TWS) Components Replacement in Cooling Water System (Case Study on PLTGU Muara Tawar Blok 1)
}

\author{
Arief Wicaksono ${ }^{1}$, Abdullah Shahab ${ }^{2}$
}

\begin{abstract}
Traveling Water Screen (TWS) in cooling water system is one of the main cooling equipment of a Combined Cycle Gas Turbine (CCGT) generator, which has a considerable impact towards the steam turbine's power output and thermal efficiency of the generator in general. This research aims to understand the distribution of TWS component failure which occurs in the filtration process of the cooling water system under the current operating condition, and operational expenditures correlated with it. The analysis started with the collection of TWS maintenance data between 2003 to 2017. Then, the distribution of failure is characterized by using available statistical software. Mathematical models were used to determine optimum replacement policy for each component, based on failure distribution data and replacement/maintenance cost. The optimum replacement interval and minimum replacement cost varies between TWS components. The optimum replacement intervals for each component are as follows: 43.4245 days for bearing bushing; 19.9785 days for bolt, sock head M.16; 40.9505 days for bolt, sock head M.12; 27.6088 days for rubber seal; 48.4359 days for pin, straight plain, 25.4 mm; 88.4978 days for ram, wiremesh; 69.471 days for pin, straight plain, 27/30 mm; and 29.2394 days for nut, hex M.8. The minimum replacement costs for each component are as follows: Rp4,383,400/day for bearing bushing; Rp5,706,850/day for bolt, sock head M.16; Rp12,671,400/day for bolt, sock head M.12; Rp7,247,630/day for rubber seal; Rp6,308,610/day for pin, straight plain, $25.4 \mathrm{~mm}$; Rp5,522,590/day for ram, wiremesh; Rp5,032,190/day for pin, straight plain, 27/30 mm; and Rp4,770,530/day for nut, hex M.8. These findings were further integrated into the implementation of optimum maintenance strategy, especially for stock control, manpower resources smoothing, and maintenance expenditure planning in order to keep the performance of the generator.
\end{abstract}

Keywords-Replacement, Optimization, Travelling Water Screen.

\section{INTRODUCTION}

Combined Cycle Gas Turbine (CCGT; or Pembangkit Listrik Tenaga Gas Uap - PLTGU) is a combination of gas turbine and steam turbine, in which the exhaust of the gas turbine is utilized to heat the steam which powers the steam turbine. PLTGU Muara Tawar ("PLTGU MTW") Blok 1

\footnotetext{
${ }^{1}$ Arief Wicaksono and Abdullah Shahab are with Department of Mechanical Engineering, Institut Teknologi Sepuluh Nopember, Surabaya, Indonesia. E-mail: arief.wicaksono@ptpjb.com; shahab_nqa@yahoo.com
}

consists of 3 units of natural gas or high-speed diesel (HSD)-powered gas turbines, 3 units of heat recovery steam generator (HRSG), and 1 unit of steam turbine, with the installed capacity of $660 \mathrm{MW}$. Several auxiliary plants were also utilized in PLTGU MTW Blok 1, such as desalination plant, water treatment plant, chlorination plant, and $\mathrm{H} 2$ plant.

PLTGU MTW Blok 1 used an open cooling system that uses seawater as coolant, and consists of 2 (two) surfacetype condenser with 2 (two) cooling water pump with the capacity of $2 \times 50 \%$. The cleanliness of the coolant, in this case the seawater, is critical in order to maintain the cooling system performance. To keep the cleanliness of the coolant that passes through the condenser, several pieces of equipment was installed. One of the installed equipment is the Traveling Water Screen (TWS).

TWS is a critical equipment: if there is a problem with the TWS unit, load shedding or even unit shut down is required in order to fix it.

PLTGU MTW used dual-flow type TWS, in which the fluid flows through both sides of the TWS to be filtered, then it goes through the cooling water line into the condenser. During the operation, TWS will rotate continuously and can be controlled either automatically or manually. Two units of TWS with the same type were installed in PLTGU MTW

Based on the unit's maintenance planning data, there are several TWS components that caused most of the TWS problems. Despite the preventive, predictive, and/or corrective maintenances, it is difficult to find the optimum maintenance schedule, due to the occurrence of corrective problems associated with one or several TWS components, which caused unit breakdown. If the maintenance is performed too often, the maintenance cost will increase. On the other hand, if it is performed less often, the risk of unit breakdown would increase, which will result in significant cost. Because of that, it is important to understand the occurrence of TWS component failure, and ultimately optimize the maintenance planning in order to reduce its cost. The TWS components which failed frequently in PLTGU MTW are shown in Table 1. 


\section{METHOD}

Equipment failure has different characteristics based on its distribution. Because of that, a proper replacement schedule is required to find the optimum component replacement time. The sooner the interval, the preventive maintenance cost will increase. On the other hand, if the component failed before the scheduled maintenance, it will cause a higher component replacement ("corrective") cost. The replacement of a component is done to restore an equipment to its original condition and function.

In general, the cost which arise due to component replacement of an equipment based on its lifetime can be summarized in Equation 1[1]:

$$
C(t p)=\frac{C p R(t p)+C f \times[1-R(t p)]}{\operatorname{tpxR}(t p)+M(t p) x[1-R(t p)]}
$$

where:

$C(t p)=$ total cost of a replacement

$\mathrm{Cp}=$ Cost of preventive replacement

$C f=$ Cost of failure replacement

$R(t p)=$ Probability of preventive cycle

$M(t p)=$ Mean time to failure

Reliability analysis was done by using Weibull++ 6 software, while the component replacement optimization to achieve minimum cost was done by using Wolfram Mathematica 11.2. The workflow of the research was as follows:

1. Convert maintenance data to failure interval data

2. Determine the distribution and failure interval using Weibull++ 6 (by comparing AvGOV, AvPlot, and LKV). After this step, a representative probability distribution for failure interval will be available

3. Determine the probability density function for failure, the rate of failure, the reliability of equipment. With that, the reliability of each equipment and the whole system can be calculated

4. Run the optimization software to determine minimum component replacement cost for the TWS

5. Determine the optimum interval and cost for component replacement

Table 2 (Equation 2-4) shows cost estimation equations that can be used to determine optimum replacement time for various data distribution type. With the suitable equation for the distribution and the appropriate cost input, the optimum replacement time with minimum average cost can be acquired. The relationship between optimum replacement time and the minimum average cost can be used to arrange an optimum preventive maintenance schedule.

TABLE 1.

PLTGU MTW'S TWS COMPONENT DATA.

\begin{tabular}{|c|c|c|}
\hline No. & Stockcode & Stockcode Description \\
\hline 1 & 815522 & $\begin{array}{l}\text { BEARING BUSHING } 38 \text { X } 42.8 \text { X } 30.5 \text { MM; ID LENGTH 80MM; CHAIN BUSH } 78 \text { EA/UNIT; MAT SUS } \\
\text { 316; PART OF TRAVELING WATER SCREEN }\end{array}$ \\
\hline 2 & 805580 & $\begin{array}{l}\text { BOLT, SOCK HEAD M16 X } 40 \text { MM; COUNTERSUNK; L KEY MAT. SUS } 31680 \text { EA/UNIT TWS; FOR } \\
\text { TWS }\end{array}$ \\
\hline 3 & 796383 & $\begin{array}{l}\text { BOLT, SOCK HEAD M12 X } 30 \text { MM; ELLEN BOLT; COUNTERSUNK MAT. SUS } 316312 \text { EA/ UNIT; } \\
\text { FOR TRAVELING WATER SCREEN }\end{array}$ \\
\hline 4 & 805721 & $\begin{array}{l}\text { SEAL } 5 \text { X } 70 \text { X } 4500 \text { MM; MAT RUBBER; RUBBER SEAL; WITH WIRE INSERTED; } 39 \text { EA/ UNIT TWS } \\
\text { FOR TWS }\end{array}$ \\
\hline 5 & 886655 & $\begin{array}{l}\text { PIN, STRAIGHT PLAIN; } 25.4 \text { X } 83 \text { MM; THREADED IN (M12) MAT. SUS 316; PIN LOCK - TIE LONG; } \\
80 \text { EA FOR TWS }\end{array}$ \\
\hline 6 & 810093 & WASHER, FLAT M8; SUS. 316 FOR TWS; 1716 EA/ UNIT TWS \\
\hline 7 & 790733 & $\begin{array}{l}\text { PIN, STRAIGHT PLAIN, 27/30 MM X 80/112 MM; MAT SUS 316; } 78 \text { EA/ UNIT TWS; FOR TRAVELING } \\
\text { WATER SCREEN }\end{array}$ \\
\hline 8 & 805770 & NUT, HEX M8; MAT. SUS 316; 1716/UNIT TWS FOR TWS \\
\hline
\end{tabular}

TABLE 2.

COST ESTIMATION EQUATION FOR VARIOUS DISTRIBUTION TYPE.

\begin{tabular}{|c|c|c|}
\hline \multicolumn{3}{|c|}{ Total Cost Estimation Equation } \\
\hline Log normal distribution & $C t=\frac{C p \int_{t}^{\infty} \frac{1}{x} e^{\left(-\frac{(\ln x-\mu)^{2}}{2 \sigma^{2}}\right)} d x+C f \int_{0}^{t} e^{\left(-\frac{(\ln x-\mu)^{2}}{2 \sigma^{2}}\right)} d x}{t \int_{t}^{\infty} \frac{1}{x} e^{\left(-\frac{(\ln x-\mu)^{2}}{2 \sigma^{2}}\right)} d x+\int_{0}^{t} e^{\left(-\frac{(\ln x-\mu)^{2}}{2 \sigma^{2}}\right)} d x}$ & (2) \\
\hline Normal distribution & $C t=\frac{C p \int_{t}^{\infty} e^{\left(-\frac{(\mathrm{x}-\mu)^{2}}{2 \sigma^{2}}\right)} d x+C f \int_{-\infty}^{t} e^{\left(-\frac{(\mathrm{x}-\mu)^{2}}{2 \sigma^{2}}\right)} d x}{t \int_{t}^{\infty} e^{\left(-\frac{\mathrm{x}-\mu)^{2}}{2 \sigma^{2}}\right)} d x+\int_{0}^{t} x e^{\left(-\frac{(\mathrm{x}-\mu)^{2}}{2 \sigma^{2}}\right)} d x}$ & (3) \\
\hline Weibull distribution & $C t=\frac{C p \int_{t}^{\infty}(x)^{\beta-1} e^{-\left(\frac{x}{\theta}\right)^{\beta}} d x+C f \int_{0}^{t}(x)^{\beta-1} e^{-\left(\frac{x}{\theta}\right)^{\beta}} d x}{t \int_{t}^{\infty}(x)^{\beta-1} e^{-\left(\frac{x}{\theta}\right)^{\beta}} d x+\int_{0}^{t}(x)^{\beta-1} e^{-\left(\frac{x}{\theta}\right)^{\beta}} d x}$ & (4) \\
\hline
\end{tabular}




\section{RESULT AND DISCUSSION}

The Time Between Failures (TBF) was acquired from PT PJB UP Muara Tawar's maintenance planning division data. As an example, the TBF for bearing bushing is shown in Table 3. Based on the TBF data for each of the TWS component, the result of 3 parameter test in Weibull ++6 to determine the most appropriate distribution function software is shown in Table 4 and Table 5.

For the bearing bushing component, which has Weibull3 distribution, the appropriate cost estimation equation is Equation 4. Using the appropriate equation, cost data input (which consists of preventive cost and corrective cost), and the component's TBF distribution parameters, the optimum replacement time which will result in minimum average cost can be calculated.

Using Equation 4 and Wolfram Mathematica 11.2 software, the optimum replacement time and cost graph for bearing bushing component was acquired. Figure 1 shows the change in bearing bushing replacement cost as a function of time. The Y-axis shows the cost in Rupiah/day, and the $\mathrm{X}$-axis shows time in days. The light green curve is the corrective maintenance cost, while the orange curve is the preventive maintenance cost, and the blue curve is the total cost which is a sum of corrective and preventive costs. The figure shows that the longer the component replacement time, the lower the preventive maintenance cost would be.
On the other hand, the corrective maintenance cost would increase if the component replacement interval is longer. The minimum total cost was found at the interval of 43.4245 days, with the average cost of Rp4,383,400 per day.

Using the same workflow, the optimum time and minimum cost for TWS component maintenance in PLTGU MTW can be calculated. Table 6 shows the results of the calculations for each component.

The optimum replacement time and minimum maintenance cost is affected by various factors, such as the price of the component, the time required to do the replacement, the amount of personnel required to do the maintenance, equipment malfunction cost, and the data distribution parameters itself. For components with similar optimum replacement interval, preventive maintenance can be done at the same time; as an example, bearing bushing, bolt sock heat M.12, and pin straight plain $25.4 \mathrm{~mm}$ has the optimum interval of 43.4245 days, 40.9505 days, and 48.4359 days respectively.

For those three components, it is better to do the replacements before the optimum time to reduce the maintenance cost. If replacements for those components are done at the same time, the maintenance cost will decrease because the equipment will be shut down only once. Note that the average cost (Rupiah/day) has to be taken into account as well.

TABLE 3.

TIME BETWEEN FAILURES (TBF) DATA FOR BEARING BUSHING

\begin{tabular}{ccccccccc}
\hline \hline \multicolumn{7}{c}{ BEARING BUSHING } \\
\hline $\mathbf{3 0 6}$ & 31 & 14 & 14 & 61 & 135 & 4 & 14 & 56 \\
$\mathbf{1 1 9}$ & 59 & 17 & 17 & 243 & 153 & 24 & 46 & 154 \\
$\mathbf{1 4}$ & 153 & 14 & 14 & 243 & 120 & 5 & 61 & 482 \\
$\mathbf{1 8 3}$ & 91 & 17 & 139 & 30 & 31 & 56 & 334 & 350 \\
$\mathbf{3 7}$ & 31 & 30 & 91 & 153 & 30 & 214 & 61 & 199 \\
$\mathbf{1 3 1}$ & 14 & 31 & 62 & 14 & 14 & 14 & 46 & 82 \\
$\mathbf{3 1}$ & 14 & 61 & 89 & 17 & 200 & 150 & 107 & 105 \\
$\mathbf{1 2 2}$ & 31 & 14 & 14 & 30 & 31 & 15 & 14 & - \\
$\mathbf{3 1}$ & 14 & 17 & 92 & 47 & 31 & 255 & 12 & - \\
$\mathbf{1 2 2}$ & 136 & 29 & 61 & 14 & 14 & 21 & 29 & - \\
\hline \hline
\end{tabular}

TABLE 4.

Distribution TEST RESULtS

\begin{tabular}{|c|c|c|c|c|c|c|c|}
\hline \multirow{2}{*}{ Component } & \multicolumn{6}{|c|}{ Ranking } & \multirow{2}{*}{ Distribution } \\
\hline & Exponential 2 & Exponential 1 & Normal & Log normal & Weibull 2 & Weibull 3 & \\
\hline Bearing bushing & 6 & 5 & 2 & 4 & 3 & 1 & Weibull 3 \\
\hline Bolt, sock head m16 & 4 & 3 & 6 & 5 & 2 & 1 & Weibull 3 \\
\hline Bolt, sock head m12 & 5 & 4 & 6 & 1 & 3 & 2 & Log normal \\
\hline Rubber seal & 6 & 3 & 4 & 5 & 2 & 1 & Weibull 3 \\
\hline Pin, straight plain; 25.4 & 5 & 4 & 6 & 2 & 3 & 1 & Weibull 3 \\
\hline Ram wiremesh & 4 & 3 & 5 & 6 & 2 & 1 & Weibull 3 \\
\hline Pin, straight plain, $27 / 30 \mathrm{~mm}$ & 5 & 3 & 4 & 6 & 2 & 1 & Weibull 3 \\
\hline
\end{tabular}




\begin{tabular}{|c|c|c|c|c|c|c|}
\hline Nut, hex m8 & 5 & & 5 & & 3 & Weibul \\
\hline \multicolumn{7}{|c|}{$\begin{array}{c}\text { TABEL } 5 . \\
\text { PARAMETERS OF THE COMPONENT's TBF DISTRIBUTION } \\
\end{array}$} \\
\hline \multirow{2}{*}{ Component } & \multicolumn{6}{|c|}{ Ranking } \\
\hline & Distribution & $\beta$ form & Scale, $\theta$ & Mean & Std dev & Gamma, d \\
\hline Bearing bushing & Weibull 3 & 1,0334 & 163,3341 & & & 1,12 \\
\hline Bolt, sock head m16 & Weibull 3 & 1,012 & 115,2667 & & & $-1,2175$ \\
\hline Bolt, sock head m12 & Lognormal & & & 3,8331 & 1,4972 & \\
\hline Rubber seal & Weibull 3 & 1,0133 & 113,5284 & & & $-0,13$ \\
\hline Pin, straight plain; 25.4 & Weibull 3 & 0,9369 & 131,1418 & & & 0,055 \\
\hline Ram wiremesh & Weibull 3 & 0,9359 & 170,2834 & & & $-0,76$ \\
\hline Pin, straight plain, $27 / 30 \mathrm{~mm}$ & Weibull 3 & 0,8537 & 172,2485 & & & $-0,265$ \\
\hline Nut, hex m8 & Weibull 3 & 0,9332 & 121,3009 & & & 0,1825 \\
\hline
\end{tabular}

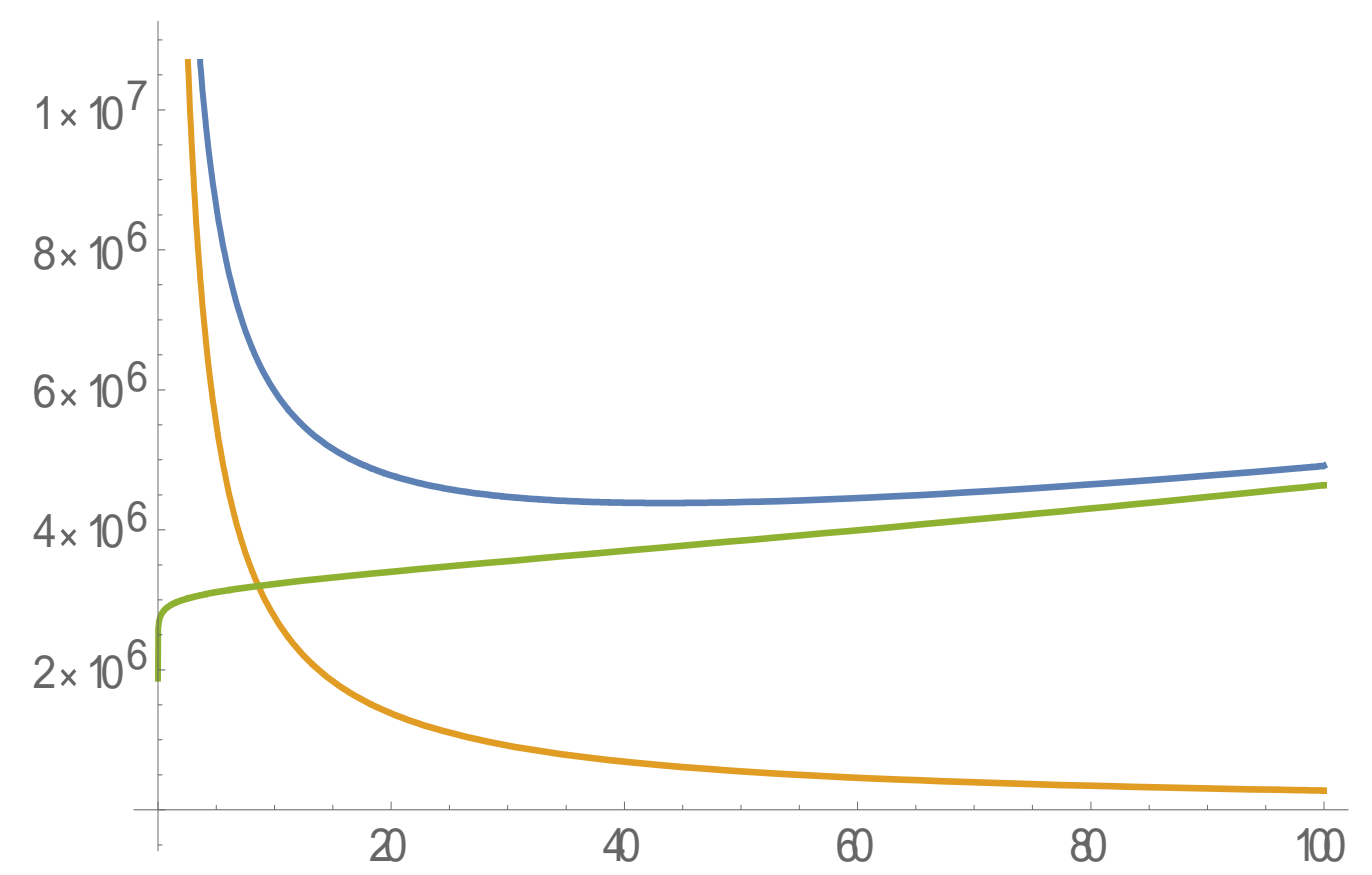

Figure 1. Bearing bushing component replacement cost plot

TABLE 6.

OPTIMUM REPLACEMENT TIME AND MiNIMUM COST

\begin{tabular}{lcccc}
\hline \hline Component & $\begin{array}{c}\text { Replacement Cost } \\
\text { (Rupiah) }\end{array}$ & $\begin{array}{c}\text { Failure Cost } \\
\text { (Rupiah) }\end{array}$ & $\begin{array}{c}\text { Average Cost } \\
\text { (Rupiah/day) }\end{array}$ & $\begin{array}{c}\text { Optimum replacement time } \\
\text { (days) }\end{array}$ \\
\hline Bearing bushing & 27.711 .600 & 565.910 .803 & 4.383 .400 & 43,4245 \\
Bolt, sock head m16 & 10.393 .600 & 565.910 .803 & 5.706 .850 & 19,9785 \\
Bolt, sock head m12 & 32.484 .264 & 565.910 .803 & 12.671 .400 & 40,9505 \\
Rubber seal & 32.508 .600 & 565.910 .803 & 7.247 .630 & 27,6088 \\
Pin, straight plain; 25.4 & 35.913 .600 & 565.910 .803 & 6.308 .610 & 48,4359 \\
Ram wiremesh & 85.593 .600 & 565.910 .803 & 5.522 .590 & 88,4978 \\
Pin, straight plain, 27/30 mm & 21.446 .328 & 565.910 .803 & 5.032 .190 & 69,471 \\
Nut, hex m8 & 17.587 .200 & 565.910 .803 & 4.770 .530 & 29,2394 \\
\hline \hline
\end{tabular}




\section{CONCLUSION AND RECOMMENDATION}

Based on the research, there are some conclusions that can be made:

1. Of all TWS components failure data at PLTGU MTW, 7 components have Weibull distribution, and 1 component has log normal distribution

2. The mathematical model used in the research, calculated by using Weibull++ 6 and Wolfram Mathematica 11.2 software, can be used to determine optimum component replacement time for TWS at PLTGU MTW

3. With the optimum replacement time and minimum replacement cost data, the interval for maintenance can be optimized. An optimum maintenance strategy will have positive impact towards inventory control and cataloguer policy, can help in manpower resource smoothing, and become an input for maintenance budget planning.
Several recommendations can be made for the power plant management team, and could become topics for further research:

1. The maintenance for the whole cooling water system in general should be improved, to decrease TWS component failure due to the failure of other systems.

2. The replacement of TWS components at PLTGU MTW should be done around the optimum replacement time to minimize the risk of component failure towards the system's operation.

3. For the components with similar optimum replacement time, preventive maintenance can be done at the same time to minimize cost associated with equipment shut down.

4. The data input and archiving of failure and/or maintenance of TWS components should be improved, to increase the accuracy of the calculations.

\section{REFERENCES}

[1] A. K. S. Jardine, Maintenance, replacement and reliability. London: Pitman, 1973. 